\title{
Filipp N. Serkov \\ (On His 100th Birthday)
}
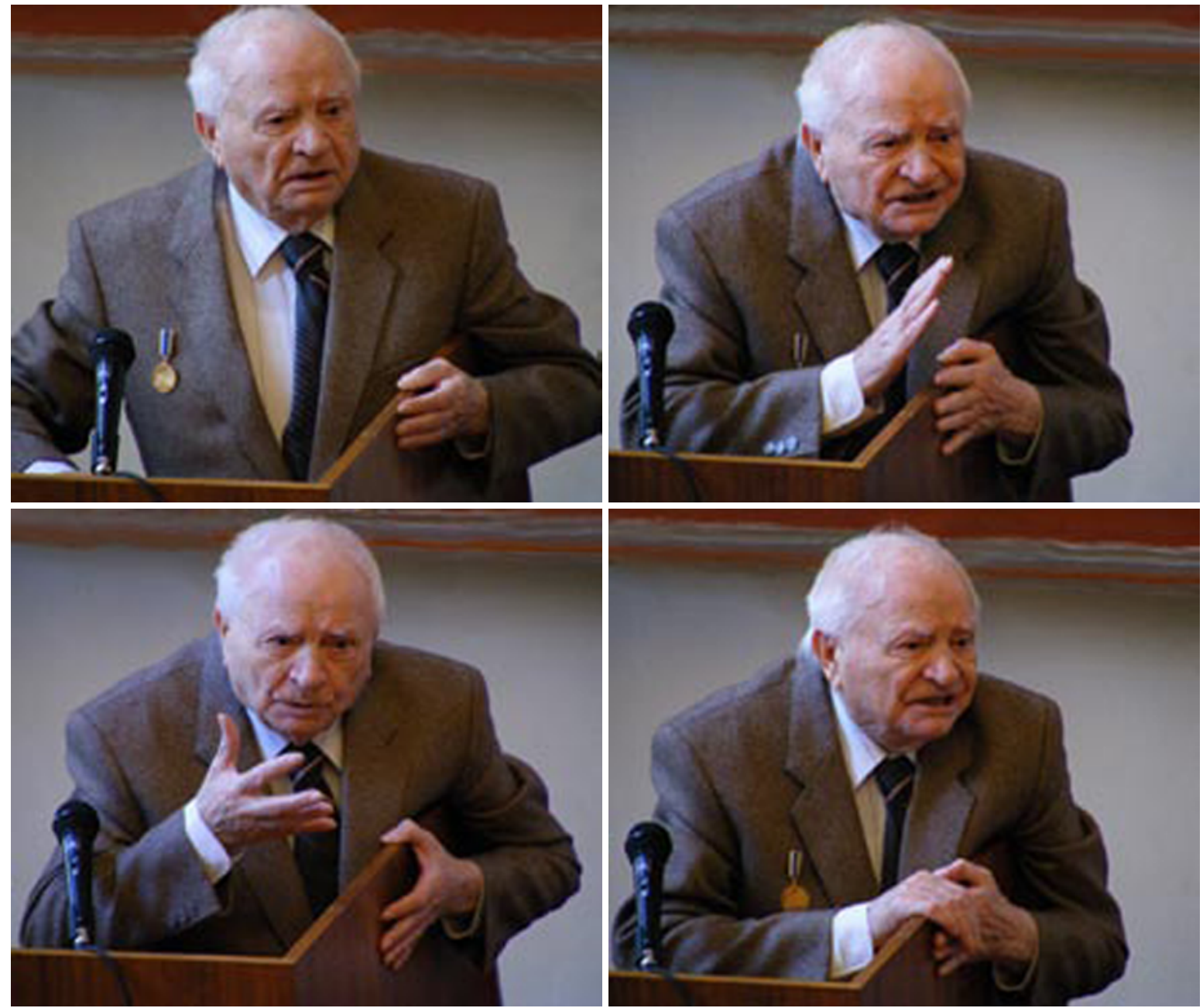

Photo by Alexander Mel'nichuk

Academician Filipp N. Serkov, a patriarch of Ukrainian neurophysiology, turned 100 on October 9, 2008.

A special general session of the National Academy of Sciences of Ukraine was convened to greet him on his centenary. Academician Filipp N. Serkov was officially rewarded the top prize of the National Academy of Ukraine for his scientific achievements, the order of "Signum of Honour," presented by Academician Boris Paton, the President of the National Academy of Ukraine. A Street in the Svyatoshin District of Kyiv was named in honor of Academician Filipp Serkov.

Academician Filipp N. Serkov also celebrated his 100th birthday at his native Bogomolets Institute of Physiology of the National Academy of Sciences of Ukraine where he worked from 1966 to 2000. On October 16, 2008, he delivered a public lecture entitled "Mechanisms Underlying Consciousness." This lecture lasted $51 \mathrm{~min}$ and was met (as all earlier lectures of this brilliant lecturer) with outstanding enthusiasm by the audience. The lecture hall was overcrowded; the lecture attracted the liveliest interest and undivided attention and was accompanied by wide discussions.

The Editorial Board of Neurophysiology/Neirofiziologiya heartily congratulates Academician Filipp N. Sekov, a Honorary Member of the Editorial Board, on his 100th birthday and cordially wishes him many years of life, good health, and good spirits. 